\title{
AUSTINIAN IFS REVISITED - AND SQUARED AWAY WITH THE EQUIVALENCE THESIS AND THE THEORY OF CONDITIONAL ELEMENTS
}

\author{
Joseph S. Fulda
}

\begin{abstract}
Austinian ifs are a relatively newly noticed linguistic phenomenon, dating only to 1951. This is in marked contrast to material implication, strict implication, logical implication, and quantified conditionals, all of which were not only noticed but thoroughly discussed, if not fully systematically formalized, by the Greeks. Since 1951, and especially since 1961 when Austin's classic 1956 paper was reprinted, they have generated a rather large literature in both linguistics and philosophy, with the more recent work often adding more in complexity than the explanatory light shed on this everyday, commonplace usage. This paper considers three simple explanations, finally settling on the third. Then, the phenomenon of "politeness conditionals," which are within the Austinian family, is discussed and a mechanism is posited as to how these work to that effect. Finally, it considers several other problematic conditionals in the general family of Austinian ifs.
\end{abstract}

[T] rained logical intuition sees a conditional behind every 'if. (Yoes, 1995: 97)

\section{Introduction.}

For the benefit of readers unfamiliar with the Equivalence Thesis or the theory of conditional elements, this section is provided. Others might well choose to gloss over it.

The Equivalence Thesis is the notion that the connective defined by the truth table for material implication is implication, at least for indicative conditionals. Put another way, what is taught in introductory logic is correct in modeling the natural-language - if... then... - construction and its synonyms by $\supset$. 
The theory of conditional elements was devised to explain apparent counterexamples to the Equivalence Thesis. A brief summary follows. According to the theory, which is entirely truth-functional and does not involve probability, not all occurrences of "if," even in the indicative mood, are simply material implication. Rather, material implication is the point-of-departure, in a sense soon to be defined, for all such occurrences.

The theory is that "if" can take on any of eight conveyances, labeled $\supset_{1}$ through $\supset_{8}$, with $\supset_{1}$ being simply material implication $(\supset)$, and the remaining seven conditional elements simply being pragmatic enrichments stronger than material implication (i.e., $\supset_{1}$ ), or so we will argue in section 4 of the present paper. Regardless, however, of which of the three explanations one might prefer, all of the other seven conveyances are logically stronger than material implication, that is, they logically imply it but are not logically implied by it, exactly as most writers argue "if" is.

A table here would be of material assistance to the reader:

\begin{tabular}{|c|c|c|c|c|c|c|c|c|c|}
\hline $\mathrm{p}$ & $\mathrm{q}$ & $\mathrm{p} \supset_{1} \mathrm{q}$ & $\mathrm{p} \supset_{2} \mathrm{q}$ & $\mathrm{p} \supset_{3} \mathrm{q}$ & $\mathrm{p} \supset_{4} \mathrm{q}$ & $\mathrm{p} \supset_{5} \mathrm{q}$ & $\mathrm{p} \supset_{6} \mathrm{q}$ & $\mathrm{p} \supset_{7} \mathrm{q}$ & $\mathrm{p} \supset_{8} \mathrm{q}$ \\
\hline $\mathrm{T}$ & $\mathrm{T}$ & $\mathrm{T}$ & $\mathrm{T}$ & $\mathrm{T}$ & $\mathrm{T}$ & $\mathrm{F}$ & $\mathrm{F}$ & $\mathrm{F}$ & $\mathrm{F}$ \\
\hline $\mathrm{T}$ & $\mathrm{F}$ & $\mathrm{F}$ & $\mathrm{F}$ & $\mathrm{F}$ & $\mathrm{F}$ & $\mathrm{F}$ & $\mathrm{F}$ & $\mathrm{F}$ & $\mathrm{F}$ \\
\hline $\mathrm{F}$ & $\mathrm{T}$ & $\mathrm{T}$ & $\mathrm{T}$ & $\mathrm{F}$ & $\mathrm{F}$ & $\mathrm{T}$ & $\mathrm{T}$ & $\mathrm{F}$ & $\mathrm{F}$ \\
\hline $\mathrm{F}$ & $\mathrm{F}$ & $\mathrm{T}$ & $\mathrm{F}$ & $\mathrm{T}$ & $\mathrm{F}$ & $\mathrm{T}$ & $\mathrm{F}$ & $\mathrm{T}$ & $\mathrm{F}$ \\
\hline
\end{tabular}

What unifies the theory is that the second line of the familiar truth table for $\supset$ is present in each of the eight conditional elements - it is the point-of-departure previously indicated. The theory is complete in that it is intended to cover all indicative uses of "if" in natural - and some extensions of natural - discourse, but incomplete in that no algorithm is provided - or likely can be provided - to tell a priori which conditional element a particular "if" might be, 
hence it is described as "more-or-less complete," depending on the perspective. Squaring away the Equivalence Thesis and this theory is, to say the least, not all that easy in the case of Austinian ifs. We suggest three simple alternatives, before finally settling on the third. Each alternative follows in its own section. Then follows a section positing a mechanism as to how "politeness conditionals," which are within the Austinian family, work to that effect. A final section deals with a variety of other problematic ifs of the Austinian family.

\section{The First Explanation.}

In some sense, this explanation appears to be the simplest of the three, yet we find it inadequate. According to this explanation, proffered me by a former colleague, "if" always retains its full truth-functional meaning at the semantic level, although at the pragmatic level the apodosis alone carries all the weight.

Thus, (1) There are biscuits on the sideboard if you want them (Austin, 1956: 113), means, literally, that the presence of biscuits on the sideboard is conditioned on your wanting them, a view Austin himself called "folly." (Austin, 1956: 113). Likewise, (2) If you don't mind my saying so, that's a pretty ugly hat (Fogelin, 1972: 579), means, literally, that the hat's being pretty ugly is conditioned on the speaker's permission to speak.

At the pragmatic level, however, (1) conveys simply that there are biscuits on the sideboard, because the context rules out, indeed all nomically possible contexts rule out the condition playing a role, there not being "enough magic in the world" to allow for telekinesis. Likewise, in all ordinary contexts, (2) conveys simply that, in the speaker's view, the hat is pretty ugly.

This view of Austinian ifs does square it away with the Equivalence Thesis and with the theory of conditional elements, rendering Austinian ifs by $\supset_{2}$ (the consequent) at the pragmatic level. 
Yet, it is too simple for my taste, for both theoretical reasons and one eminently practical reason, the latter itself suggesting a theoretical defect.

At the theoretical level, it would make my colleague a clear disciple of Jacob L. Mey (2010), who writes in his $\$ 4$ (p. 2884) that "by starting out from semantics, ..., we are putting the semantic cart before the pragmatic horse," and as Mey continues, it's not merely a case of what has been called "pragmatic intrusion" into semantics, but rather "[p]ragmatics always comes first, and pragmatics constrains semantics, not the other way around," exactly the sort of "radically pragmatic" view one would expect of the dean of pragmatics. However, this is not my view, and never has been. I have no wish, to cite the title of a significantly less radical book, to engage in the task of "making semantics pragmatic."

Yet, this is what this view does, notwithstanding clearly contrary appearances. For to understand (1) in the "literal" way indicated, it is absolutely essential to presuppose - start with - a particular (class of) context(s), and one in which our nomic laws simply do not hold. (Of course, it is true that as meaning is given by truth conditions - on my view, at any rate - if "There are biscuits on the sideboard" is taken as given, then any antecedent will do. If the antecedent is false, we have a vacuously true statement; if it is true we have a non-vacuously true statement. But this is not what my former colleague meant, because it does not explain at all the purpose of the antecedent as given - which, on his stated view, does require a magical world. Now, I don't deny what I endorsed in Fulda (2010), namely Thomson (1990: 69) "Plainly then, it will not do to import the reasons for which the conditional is asserted into the meaning of the conditional." The point here, however, is to give not simply the meaning or truth conditions of the entire sentence but of both parts of it, and the first part creates problems with an ordinary world. See note 4 here, as well. Furthermore, Thomson's case has three different sets of reasons for uttering the conditional as 
a conditional, which he describes as "cogent but dull," "not dull but silly," and "cogent, and far from silly." Thus there is some reason for uttering both the antecedent and the consequent in a conditional, no matter the perspective. But, under ordinary circumstances, as Rieger (2006) points out, conditionals are not assertible if one knows either the antecedent or the consequent or the denial of the antecedent or the denial of the consequent. Without a magical world, the conditional, if taken as a properly compositional conditional, ought not to be assertible.) When one is constrained by the literal meaning of the antecedent to presuppose a "magical" context nowhere so much as adumbrated in the text, one is willy-nilly not putting semantics first, after all. In precise accordance with Mey (2010), interpreting (1) in this manner is a clear example of "pragmatics constrain[ing] semantics." Second, this is not merely a radically pragmatic view, but also a radical view of truth-theoretic semantics, as well. As Davidson (1986: 434) makes clear "I take for granted, however, that nothing should be allowed to obliterate or even blur the distinction between speaker's meaning and literal meaning." Yet this presupposition of a nomically impossible context for the antecedent so divorces speaker meaning, across all speakers, from sentence meaning as to "obliterate" the former from the horizon of the latter. Why? Because, although speaker meaning will frequently differ from sentence meaning, depending not just on speaker intent, but also on auditor understanding and the overall context, the situation here is quite different, for there never was even a single speaker of the English tongue whose meaning in uttering such a sentence coincided with the sentence meaning so given. Yet, this is neither poetry nor metaphorical speech but a usage in everyday employment which is very well understood, in some more appropriate sense of "literal," more on which in section 4. So this view appears to be at once radically pragmatic and radically semantic. Davidson's whole program is motivated by a rather simple argument, although the program itself is not as simple. That argument is that given only a 
finite number of words at our disposal and notwithstanding this our clear ability to understand an infinite number of sentences, including those we have never even imagined hearing before, what he calls "first meaning," (p. 434) semantics or literal meaning, must, of necessity come first. How do we understand an infinite variety of sentences? Davidson (1986: 436) gives three principles, the first of which is the existence of a recursive or inductive definition (as explained by him on p. 437) by which well-formed sentences are built from a finite number of words. (When applied to meaning, as opposed to syntax, it is now more customary to call this phenomenon "compositionality," although the two words or phrases can be used at either the syntactic or the semantic level.) This is what makes languages learnable, a common argument in favor of compositionality.

At the practical level, a theory of a simple phenomenon must not be either far more complex than the phenomenon it purports to explain, nor again so simple as to fail that most elementary test, the classroom. If a theory is bound to create some laughter in the more-competent students who, however, are not yet trained to be over-sophisticated - as would no doubt happen were I to propound it in some such class - the theory is probably best avoided and, indeed, may well be an indication of theoretical troubles that although the class cannot pinpoint, they nevertheless intuit.

\section{The Second Explanation.}

The second explanation, endorsed in Fulda (2010) and explained further in Hernández and Fulda (2012), fits just fine with the theory of conditional elements, but not nearly as well with the Equivalence Thesis. This is the view that in pure Austinian ifs such as (1), the antecedent plays no truth-functional role, with both the semantics and the pragmatics collocated solely in the consequent. Hernández 
and Fulda (2012: 329, fn. 1) referred to this as "semantics-pragmatics collapse." It might fairly be asked what role at all pragmatics plays. If the antecedent plays no semantic role, and is to be written off as rhetorical rather than logical, then why should the consequent be anything other than simply semantic? The answer, of course, is that most Austinian ifs are not pure - but rather what Austin himself called "ifs of doubt or hesitation" (Austin, 1956: 114, based on the etymology of "if"), the prototypical example of which is (3) "If memory serves, the capital of Honduras is Tegucigalpa" (Geis and Lycan, 1993: 48), dubbed in Fulda (2009: \$3) "bridge conditionals." This may or may not be an indication of true doubt or hesitation. If it is, then a full-fledged conditional with its meaning given standardly by material implication is indicated. If it is not (see Fulda (2009: 1443) on why it may not be such), then the conveyance is simply the consequent, $\supset_{2}$. But what can possibly tell one whether a given Austinian if is pure or not, and if not pure, whether it does or does not retain its full truth-functional meaning, $\supset$ ? Sometimes, the text will tell us, but at other times contextual information will be required. It is context, for example - our existence in a world in which telekinesis is not (presently) possible - that rules out a truth-functional role for the antecedent in (1) and context that may or may not rule out such a role for the antecedent in (2) ${ }^{1}$ and (3). Because of this "may or may not," the example selected in Fulda (2010) was one which is clearly "pure"; the sole role of pragmatics in such an Austinian if is to deny a semantic role to the antecedent. In ordinary "ifs of doubt or hesitation,"2 the role of pragmatics is larger - deciding whether $\supset_{1}$ or $\supset_{2}$ is being conveyed. However, this is most definitely not putting pragmatics first, because the nominal antecedent is, indeed, understood first as what it literally means, and then the nominal consequent is likewise understood as what it literally means. After this first meaning is grasped, it becomes evident that an attempt at compositionality is out of order, and the nominal antecedent can play no truth-functional role. 


\section{The Third Explanation.}

Neither of these explanations, simple as they may be, is genuinely satisfying. The best explanation that is both simple and elegant is based on Fogelin (1972) as modified by Fulda (1999, 2009), which is further modified here. I abandoned that explanation in the discussion in Fulda (2010) due to a most elementary error missed by not only this author, but also by the generally high caliber of referees who were of material assistance in my numerous other papers in both of those journals. I cannot say what happened in 1999 , since that paper was accepted almost as is. However, in 2009, there were several foci of discussion that were not even remotely germane to what the paper sought to do.

One focus was on whether it is a more fitting tribute to J. L. Austin to name the phenomenon he first noticed after him (my view), as Fogelin did, or whether it is a more fitting tribute to name that phenomenon after one of his country's prototypical foods (biscuits), as the more recent treatments do. A second focus was on why I chose not only not to ignore DeRose and Grandy's (1999) work, but also to open the paper with an epigraph from their piece, while completely disregarding some newer work. The epigraph itself answers that question:

[I]f [Austinian ifs] are to be handled at all by any leading theory of conditionals, it will have to be an account of "indicative" conditionals. But the leading theories of indicative conditionals, we believe, are not up to the task. ... [T] he best case scenario, of course, is for there to be a unified theory which can account for both kinds of conditionals, while also respecting, and even explaining, the significant differences between them. Fortunately, the general theory of indicative conditionals that we endorse ... does just that.

Of course, we noted that DeRose and Grandy endorse a different general theory. 
The newer works disregarded are simply not theories of indicative conditionals per se, and thus make no attempt to unify different varieties of same, but are rather stand-alone attempts to treat Austinian ifs as a class apart from other indicative conditionals. This, in turn, violates the "trained logical intuition" cited in the epigraph of the present paper.

Still another focus was on how what was genuinely new in the 2009 paper (as opposed to the 1999 paper), the treatment of conditionally self-falsifying utterances, related to Austinian ifs (it didn't, and I said so in black and white, in the abstract yet) and on how the particular example I used therein of such an utterance could possibly hold of a person with senility (it could not so hold, and same was ruled out by stipulated contextual condition (D) on p. 1445).

With all these extraneous foci, it is little wonder that I ensured that the tentativity of the paper would come across with unparalleled clarity. It is, after all, my sole technical paper which begins with the word "Towards"3 and it contains the following clear disclaimer on p. 1441:

I am certain that the theory has several unattractive features as well; this is why I speak of an 'attempt'....

Similarly, the paper closes with "If I'm right about most of this, ...." (p. 1447), which, I assure the reader, expressed true doubt and hesitation!

Likewise, it is little wonder that the proper job of referees - spotting errors missed by the authors and then deciding whether they prove fatal or easily (or not-so-easily) repaired - was left undone. One error, the substitution of either $\supset_{2}$ or $\supset_{4}$ for $\supset_{8}$ was repaired in Fulda (2010: 466, text and fn. 12). The other error, though far more minor and a commonplace among both students and scholars, is nonetheless far more embarrassing: It is nothing more and nothing less than the logician's nightmare - a scope error. Let us elaborate. 
In Fulda (2009: 1442) I took the position of Peetz (1974: 594) that Fogelin was "successful" but also that not "all of his expansions [are] satisfactory"4 and more-or-less correctly translated Austin's (1) with "If you want them, I'll tell you where they are: There are biscuits on the sideboard." I then withdrew this, as a key part of the theory of conditional elements ${ }^{5}$, because $(p \supset s)$ $\wedge \mathrm{q}^{6}$ does not qualify as $\supset_{4},{ }^{7}$ which is certainly true. Had I written the ever-so-slightly, but most-importantly different formulation "If you want them, I'll tell you where they are - there are biscuits on the sideboard," the translation would have been, instead, $\mathrm{p} \supset(\mathrm{s} \wedge \mathrm{q})$, and as argued for at length in Fulda (2009: \$4), based on their denials, $s$ and $q$ have the same propositional content (although different discourse functions), giving us $\mathrm{p} \supset(\mathrm{q} \wedge \mathrm{q})$ or, simply, $\mathrm{p} \supset \mathrm{q}$, but conveying only $\mathrm{s} \wedge \mathrm{q} \equiv \mathrm{q} \wedge \mathrm{q} \equiv \mathrm{q}$, exactly as required. In other words, contrary to Fogelin, it is not that the consequent is suppressed, but that part of it is. In still other words, the consequent is elliptical. As Yoes (1995: 98) says of (1) "[T] here is no doubt that [it] is in some way incomplete" and "There is ellipsis here." The question is "Where?" Both Fogelin and Yoes were certainly on the right track, but we have now added, in this third and final explanation, exactly the way (1) is incomplete and where the ellipsis is.

This is also part of what is wrong with the first explanation. It, too, presumes ellipsis, with the word then, which is nearly universally agreed as out-of-place between antecedent and consequent in an Austinian if (see note 9, infra), elided, and then compositionality is used by presupposing a nomically impossible context for the likes of the antecedent of (1) and a very odd context for the likes of the antecedent of (2). But since the word "then" is not actually in (1) or (2), it is not an appropriately literalist way to understand even the first meaning. Granted there is ellipsis in both (1) and (2), but the first explanation does not adequately locate it. 


\section{How Do Politeness Conditionals Work?}

As already discussed, in his study of Austinian ifs, Fogelin (1972: 579, ex. 7) offers the following example, "If you don't mind my saying so, that's a pretty ugly hat." As the protasis has nothing whatsoever to do with the apodosis, he takes this as elliptical for "If you don't mind my saying so, I will: That's a pretty ugly hat." ${ }^{8}$ It is well-known that with Austinian ifs, because of the disconnect between protasis and apodosis, the typical "then" that begins the apodosis cannot be interposed. (See, for example, Geis and Lycan, 1993, p. 36, condition A). ${ }^{9}$ Fogelin's expansion does allow the interposition of a "then," albeit only at the start of the elided apodosis.

Left unexplained - and this is no criticism of Fogelin, for that was no part of his purpose - is what purpose the protasis (and elided apodosis) serve, to which the obvious answer is politeness, a softening of the blunter, more direct "That's a pretty ugly hat," which is all that is actually conveyed by the entire utterance.

The purpose of this section is to posit a mechanism as to how this circumlocution succeeds in doing so. In a phrase, "conditional perfection." In other words, the speaker is really implicating, also, "Only if you don't mind my saying so, I will: ...." or, alternatively and one might think equivalently, "If you do mind my saying so, I won't: ...." with the further implicature that if the auditor does mind, it should be considered unsaid. Whether or not this further implicature will be accepted by the auditor is, of course, up to the auditor.

Another example beyond Fogelin's would be of use:

(4) If you don't mind, I am trying to read.

which means "If you don't mind, [since I am trying to read now] I'll just keep on reading," but: 
implicates, first, if you [really] do mind, I will stop trying to read [and deal with your agenda, whatever it may be] and, at a second level, if you really don't mind, I will just keep reading, after all, with, again, the decision left to the auditor.

In her exceptional study of the differences between conditional perfection mediated via "only-if" and conditional perfection mediated via "if-not, then-not," Van Canegem-Ardijns (2010) does not consider either Austinian ifs, generally, or the sub-type we have here dubbed "politeness conditionals," in particular. But if Fogelin is right, and I believe he is (subject to the modifications in Fulda (2009: $\$ \$ 2,4)$ and the further modifications in the preceding section - and see also $\$ 6.1$ ), then the actual, if elided, apodosis is simply "I will." That, in turn, makes the part of the utterance that is conditional, elided apodosis included, a gardenvariety conditional, albeit one with a politeness function. But the sort of garden-variety conditional it is meets all of Van CanegemArdijns' requirements for mediation of conditional perfection via "if-not, then-not," listed in her fn. 6 (p. 6):

(i) the speaker may be taken to believe that in situations in which $\mathrm{A}$ is not the case, $\mathrm{C}$ will not be the case as a result; (ii) the speaker may be taken to have the intention to inform the addressee about this belief; (iii) the information that if not- $A$, then not- $C$ is relevant in the context of the speech act performed by the speaker. ... A good reason for such an assumption is that the speaker supposes that the action/event mentioned in $\mathrm{C}$ is (un)desirable for the addressee.

where A indicates "antecedent" and C indicates "consequent" and changing only the first of the three conditions just quoted from "C will not be the case" to "C will not be taken to be the case," which is what politeness requires of the speaker. ${ }^{10}$ In 
marked contrast, this garden-variety conditional palpably fails to meet Van Canegem-Ardijns' very first condition for mediation of conditional perfection via "only-if" (p. 5): "S[peaker] considers C desirable for $\mathrm{H}$ [earer] because $\mathrm{S}$ assumes $\mathrm{H}$ wants $\mathrm{C}$ or $\mathrm{S}$ wants C..." Of course, the whole point of the "politeness conditional" is that the speaker is quite uncertain that $\mathrm{C}$ is desirable for the hearer - although he may feel it nonetheless necessary for the hearer to, in fact, hear it, notwithstanding its being undesirable. This garden-variety conditional even more palpably ${ }^{11}$ fails to meet Van Canegem-Ardijns' final condition for mediation of conditional perfection via "only-if': "A is supplied by the speaker as a necessary condition or 'precondition' on the performance of the speech act about C."

Now, we ask, given the slight modification of condition (i) in Van Canegem-Ardijn's scheme for conditional perfection mediated via "if-not, then-not" whether she remains right that conditional perfection implicatures so arising are not cancellable without involving the speaker in some form of pragmatic paradox. Although her analysis - which, as noted, does not deal with "politeness conditionals" - cannot be carried over without extensive modifications, her conclusion can be!

It seems distinctly odd - in light of the obvious politeness function - to add in "If you don't mind my saying so - and even if you do - that's a pretty ugly hat," because as she argues that would violate the sincerity condition (p. 10) and would, in fact, turn what starts as a "politeness conditional" into an even ruder statement than "That's a pretty ugly hat" alone would be. Likewise, it would be odd - in light of the obvious politeness function - to add in "If you don't mind - and even if you do - I'm trying to read," because, again, as she argues that would violate the sincerity condition (p. 10) and would, again, turn what starts as a "politeness conditional" into an even ruder statement than "I'm trying to read" alone would be. 


\section{Certain Other Problematic Ifs of the Austinian Family.}

In the previous section, I dealt with what I dubbed "politeness conditionals" focusing, however, exclusively on how they work to that end and Hernández and Fulda (2012: 330,\$3) severally realized and jointly published a view of concessive conditionals that differ in their key terms. I want to say a few words here on the proper expansion of "politeness conditionals," make some remarks on an example suggested by an anonymous referee, deal with concessive conditionals that don't differ in their key terms, and deal, finally, with yet another difficult case in this general family.

6.1 In my view, the proper expansion of such as (2) remains what it has been since Fogelin (1972) discovered it as endorsed in Fulda (2009): "If you don't mind my saying so, I will: That's a pretty ugly hat." Now, this is quite different from (1). It is, indeed, $(\mathrm{p} \supset \mathrm{s}) \wedge \mathrm{q}$, where the propositional content of $s$ and $\mathrm{q}$ are markedly different, and the entire consequent is suppressed, rather than merely part of it. Put differently, "politeness conditionals" make two separate (if conjoined) statements, the first a conditional, the second an atomic proposition, with the former meta-linguistically applying to the latter, for purposes explained in the previous section. ${ }^{12}$

6.2 An anonymous referee asked me how I would treat "It was a great article, if I may say so myself." Of course, this is not a "politeness conditional," so what then is it? In my view, it is an unusual variety of concessive conditional where the antecedent and consequent differ in their key terms. That is, the conveyance is $\sim \mathrm{p} \wedge \mathrm{q}$ or $\supset_{6}$. In words, "[Although] I may not [with propriety] say so myself but it was a great article," where what is being conceded is the immodesty of asserting the consequent of one's own work.

6.3 Left untreated (since 1999) by this author are concessive con- 
ditionals that don't differ in their key terms. An early source of one such cited by Yoes (1995) is Adams (1988: 122): "If it rained it didn't rain hard." The problem with this, as Adams' title indicates, is that if it turns out it did rain hard, then by Modus Tollens, it didn't rain at all, a plainly nonsensical position. Adams, of course, favors a probabilistic treatment for this and other cases, which by now has become the dominant view - that conditionals are suppositions to be treated probabilistically. My preference, here, is again with Fogelin - who, however, did not treat this type of case - exactly as given in 1999: If it rained, it rained, but it did not rain hard. This, too, (i.e., like "politeness conditionals") conjoins an atomic proposition with a conditional, but with a twist. The word "but" often indicates concession, and it does so here as well. But exactly what is being conceded here? One promising possibility (without additional context) is that the conditional concedes lack of interest in whether ordinary rain fell or not (this should hardly be surprising since it is tautological $-p \supset p$ ), whereas what really interests the speaker is contained in the atomic proposition, which is denied - namely whether hard rain fell or not. Another promising possibility is that what is being conceded is that ordinary rain may or may not have fallen - but that regardless hard rain did not fall. (This is symbolized a bit differently: $(\mathrm{p} \vee \sim \mathrm{p}) \wedge \mathrm{q}$, which, however, is logically equivalent to $(\mathrm{p} \supset \mathrm{p}) \wedge \mathrm{q}$ and which also conveys merely q.) I should note that not all conditionals that don't differ in their key terms are concessive; many are ordinary material conditionals: Thus, "If it rained, then it rained hard" presents no problem of any type (for Modus Tollens or any other of the standard logical rules of inference), and is simply $\supset$, not a conjunction of a conditional and an atomic proposition. ${ }^{13}$

6.4 Given that, as we have seen, some ifs of the Austinian family are best represented as $(\mathrm{p} \supset \mathrm{s}) \wedge \mathrm{q}$ and others as $\mathrm{p} \supset(\mathrm{s} \wedge \mathrm{q})$ and that making sense of the sentence requires disambiguation as to scope 
and that this must take place before one can understand what is stated, let alone any pragmatic loading, am I, too, advocating a view that is radically pragmatic? I should hope not. Rather, such cognitive decoding is normally required prior to semantics, as Kuczynski (2010) has beautifully explained - this decoding is what he terms "presemantic" rather than what is standardly meant by "pragmatic." Indeed, Davidson (1986: 436) concedes that disambiguation is among the challenges for the literalist view, ${ }^{14}$ a problem neatly solved using Kuczynski's framework.

The one case where it may appear that I have endorsed something of a radically pragmatic view is Fulda (2010: 464, example (9) exemplifying $\supset_{5}$ ) where I used an apparently ${ }^{15}$ nomically impossible consequent, viz. "I'm a monkey's uncle" in order to avoid giving offense to the many good people of Dutch descent. The difference is, even apart from note 15 , it is immediately recognized that this consequent is impossible and Modus Tollens is promptly performed, and the speaker meaning is immediately understood as $\supset_{5}$, even though it differs from the sentence meaning which remains $\supset$. (The immediate recognition arises from its being a dead metaphor for falsity. ${ }^{16}$ ) In a "pure" Austinian if, in contrast, the alleged literal sentence-meaning has never been understood as a condition by any native speaker of the English tongue. As Fogelin (1972: 578) writes, "I shall ... take it for granted that we can recognize [Austinian ifs] when they come along."

6.5 Now, what about what verily appears to be a mere rhetorical flourish contradicting our opening epigraph, the virtually omnipresent "if you will"? This is, again, different. Here, neither the consequent in its entirety is suppressed nor again is it partially suppressed. Rather, here it is the antecedent that is elliptical, indeed just about truncated with its main sense left for the reader or the auditor. As is usual (with me), the text itself should be the first means of supply- 
ing whatever is elliptical and anything in the background a second, and secondary, means.

Four examples, if you will. The first has just been given and "filled in" means something like "if you will please bear with me," a "politeness conditional." A second example: "That's a positively awful outfit, if you will." This is, again, a "politeness conditional" where the antecedent filled in means something like "if you will tolerate my saying so." A third example: "I will call this class of conditionals 'bridge conditionals,' if you will." This, filled in, means something like "if you will allow me the liberty of coining a phrase." This is not a "politeness conditional," but is rather, once more, a variant form of concessive conditional where the antecedent and consequent differ in their key terms. What is conveyed is "I will call this class of conditionals 'bridge conditionals' but [in so doing] you will [have to] allow me the liberty of coining a phrase," i.e. the conveyance is $\mathrm{p} \wedge \mathrm{q}$ or $\supset_{4}$. Finally, sometimes "if you will" is just barely elliptical, meaning simply "if you are willing." In such cases, the condition (and conditional) is ordinary, and the conveyance is no different from the literal meaning, $\supset$.

6.6 Postscript. The theory endorsed here in $\$ 4$, as well as this final section, depend heavily on ellipsis. This should not be surprising, at least coming from the present author. Long before the very first paper on the theory of conditional elements was written back in 1999, a theory of imperatives reducing them to a form of - what else - conditionals, which even more heavily, nay much more heavily, relies on ellipticality was put forth in Fulda (1995). In other words, in my view, language is often elliptical, with some or much of the sense to be grasped by the reader or auditor, even at the literal level. The difference between what was put forth in 1995 and the theory of conditional elements is that it is, at least in principle even if not algorithmically, possible to "fill in the 
blanks." In the 1995 paper, even the speaker may not know (while speaking) how to do so.

\section{Acknowledgments}

This piece was refereed in two stages; the first covering only section 5 , the second covering the remainder. An informal referee was of some assistance and is to whom the second point in note 13 is also due.

\section{Notes}

1. Certain special contexts, such as a classroom - or, for that matter, throne room - where certain comments about the appearance of the person on the raised platform or throne are strictly forbidden may allow for the full truth-functional meaning, but then the final point of note 12, infra, does not apply.

2. Of course, I am not saying that Austin - or anyone else making such a claim about biscuits - has no doubt or hesitation about whether the addressee wants them; they are pure, rather than ordinary, only in the sense that the doubt or hesitation is not actually a condition on which the truth of the nominal apodosis depends.

3. My book Eight Steps towards Libertarianism (Bellevue, Wash.: Free Enterprise Press, 1997) is, in fact, the only occurrence - I believe - where "towards" is anywhere in the title, but there the word indicates something entirely different. Specifically, in that restatement of American principles, I deal extensively with the proper aims and scope of government, but suggest no way to get there for the simple enough reason that I do not know how to accomplish such a daunting task, and, as briefly discussed therein, the American Framers, who believed they had the answer to that difficult question through an ingenious institutional framework, commonly known as checks and balances - division of powers and separation of powers - did not in fact have a long-lasting (given the scope of history) answer as to how to constrain government to these aims and scope. 
4. I do not doubt that in ordinary contexts both Fogelin and Yoes are correct in that (1) grants permission to the auditor to take some biscuits; where I differ from them is that this is merely an implicature and not part of the sentence meaning. Austin himself rejected this, too, but for entirely different reasons.

5. I, did, however, retain it as an explication of Austinian ifs - see Fulda (2010: 463, close of $\$ 4$ ).

6. $s$ stands for "suppressed."

7. Because, as I put it in Fulda (2010: 463), "not all conjunctions are (properly so-called) $\supset_{4} . "$

8. Modified very slightly from "That's a pretty ugly hat and if you do not mind my saying so, I will."

9. Geis and Lycan (fn. 2) attribute this observation to at least as far back as a 1979 paper by Alice Davison, but it may go back even further.

10. This does apply to (4) as well, because of the word "trying." In other words, the speaker is implicating that he will take it as if he were not trying to read. Nonetheless, the same would be true were "trying to read" to be replaced by simply "reading."

11. "Even more palpably" because if the speaker truly considers it necessary for the hearer to hear it, then it may be desirable for the hearer to hear it, even though not actually desired by the hearer. In other words, "desirable" in that first condition for mediation via "only-if" is perhaps a bit ambiguous.

12. As I explained those purposes, and how they might work, I am bound to agree with Fogelin (1972: 579): "It is no objection that in the first part of this utterance we come right out and say the very thing we ask permission to say in the second part"; our explanation of "politeness conditionals," in other words, is insensitive as to order. See note 8, supra, for Fogelin's original rendition. The only qualification I would make to this is that it is, of course, not permission, properly so-called, that is being sought. See note 1, supra.

13. This whole subsection departs modestly from formal logic, properly socalled, which is the logic of forms. Once one speaks of "key terms" being different or the same, one departs from the form of the statement and ventures into its content. As we have just done it though, it is merely a modest departure, because understanding the terms, their semantics, is not required in these cases; syntactic rules will do to make this determi- 
nation. However, one can use different words that amount to the same thing, synonyms or near-synonyms, in which case the departure would be more than modest.

Second, there is a far better way of resolving Adams' apparent counterexample to Modus Tollens than we have presented here, but as it belongs to someone else and is not published at the time of this writing, the reader is left with simply this affirmation.

14. Davidson refers to lexical ambiguity, rather than scopal ambiguity, but as I see it, both present similar challenges to the literalist view. Of course, to say that something presents a challenge is most certainly not to say that the challenge is insurmountable. Various authors have written on how to deal with lexical ambiguity within the truth-conditional view, while others have treated the issue of the scope of quantifiers extensively. If one understands quantifiers as expansions over the domain of discourse (conjunctive for universal quantification, disjunctive for existential quantification, and in language as opposed to ordinary, classical logic there are numerous other quantifiers as well), then it is certainly plausible that the type of ambiguity with which we are concerned here, the scope of connectives, can be resolved by appropriate adaptations of the work on the scope of quantifiers.

15. I say "apparently" because primates can be trained to keyboard - after the adage, "monkey see, monkey do" and then some (learn) - and could therefore write, if not vocalize, such a conditional.

16. By this, I mean analytic falsity, not logical falsity.

\section{References}

Adams, Ernest W. 1988. Modus Tollens Revisited. Analysis 48(3).122-128. Austin, J. L. 1956. Ifs and Cans. Proceedings of the British Academy 42.109132.

Davidson, Donald. 1986. A Nice Derangement of Epitaphs in Part VI, Limits of the Literal of Ernest LePore, ed., Truth and Interpretation (Oxford and New York: Basil Blackwell), pp. 433-446. 
DeRose, Keith and Richard E. Grandy. 1999. Conditional Assertions and "Biscuit" Conditionals. Noûs 33(3).405-420.

Fogelin, Robert J. 1972. Austinian Ifs. Mind 81(324).578-580.

Fulda, Joseph S. 1995. Reasoning with Imperatives Using Classical Logic. Sorites 3.7-11.

Fulda, Joseph S. 1999. Broadening and Deepening Yoes: The Theory of Conditional Elements. Sorites 10.15-18.

Fulda, Joseph S. 2009. Towards a Unified Theory of 'If's - The Theory of Conditional Elements: Further Evidence from Conditionally SelfFalsifying Utterances. Journal of Pragmatics 41(7).1440-1448.

Fulda, Joseph S. 2010. The Full Theory of Conditional Elements: Enumerating, Exemplifying, and Evaluating Each of the Eight Conditional Elements. Acta Analytica 25(4).459-477.

Geis, Michael L. and William G. Lycan. 1993. Nonconditional Conditionals. Philosophical Topics 21(2).35-56.

Hernández Ortiz, Héctor and Joseph S. Fulda. 2012. Strengthening the Antecedent, Concessive Conditionals, Conditional Rhetorical Questions, and the Theory of Conditional Elements. Journal of Pragmatics 44(3).328-331.

Kuczynski, John-Michael. 2010. Intensionality, Modality, and Rationality: Some Presemantic Considerations. Journal of Pragmatics 42(8).23142346.

Mey, Jacob L. 2010. Reference and the Pragmeme. Journal of Pragmatics 42(11).2882-2888.

Peetz, Vera. 1974. Fogelin on Austinian Ifs. Mind 83(332).594-595.

Rieger, Adam. 2006. A simple theory of conditionals. Analysis 66(291).233240.

Thomson, James F. 1990 [1963/1964]. In defense of ' $\supset$ '. The Journal of Philosophy 87(2).57-70.

Van Canegem-Ardijns, Ingrid. 2010. The indefeasibility of the inference that if not-A, then not-C. Journal of Pragmatics 42(1).1-15.

Yoes, M. G. 1995. When Is If? Sorites 1.96-99. 
